\title{
Expressão do mRNA para IGF-2 em oócitos e células do cumulus extraídos de folículos antrais e pré-antrais de ovelhas nativas do Estado de Pernambuco ${ }^{1}$
}

\author{
Arthur N. Melo²*, Edivaldo R. Santos Júnior², Diogo F. Silva³, Manoel Adrião4, \\ Ana L.F. Porto ${ }^{4}$ e Aurea Wischral ${ }^{5}$
}

\begin{abstract}
Melo A.N., Santos Júnior E.R., Silva D.E., Adrião M., Porto A.L.F. \& Wischral A. 2017. [IGF-2 mRNA expression in oocytes and cumulus cells of antral and preantral native sheep follicles in Pernambuco State, Brazil.] Expressão do mRNA paraIGF-2 em oócitos e células do cumulus extraídos de folículos antrais e pré-antrais de ovelhas nativas do Estado de Pernambuco. Pesquisa Veterinária Brasileira 37(5):526-530. Núcleo de Educação em Ciências Agrárias, Universidade Federal de Sergipe, Avenida 26 de Setembro 1126, Nossa Senhora da Glória, SE 49680-000, Brazil. E-mail: arthurnascimento@gmail.com

The aim of this study was to analyze the mRNA expression of IGF-2 growth factor in oocytes and cumulus cells from native sheep follicles at different stages of follicular development. The classified morphologically as antral follicles (tertiary preovulatory) were aspirated manually to obtain the oocyte and the cumulus cells. The preantral follicles (secondary) were extracted from the ovarian cortex by microdissection, and oocytes were removed. In both groups, oocytes were denuded and grouped into "pools" of ten cells each (Group A, n=10, Group B, $n=10$ ) and ten samples with groups of cumulus cells (Group A1, n=10; $B 1, n=10$ ). The mRNA was extracted and converted to cDNA using the RT-PCR technique. The expression analysis confirmed the expression of IGF-2 gene for groups of oocyte and the cumulus cells. There was an increase in the relative expression of mRNA for IGF-2 for groups of oocytes during the later stage of follicular development and differences were considered significant $(p<0.05)$. There was no significant variation in the expression of IGF2 between groups of cumulus cells. It is concluded that the growth factor IGF- 2 has higher levels of expression in sheep oocytes in the second stage of follicular development in the conditions adopted and similar expression in cumulus cells during various stages of follicular development.
\end{abstract}

INDEX TERMS: IGF-2 mRNA, oocytes, cumulus cells, follicles, PCR, gene, sheep, Santa Inês.

RESUMO.- Objetivou-se avaliar a expressão do mRNA para o gene do fator de crescimento IGF-2 em oócitos e células do cumulus de ovelhas em diferentes estágios do desen-

\footnotetext{
${ }^{1}$ Recebido em 27 de agosto de 2016.

Aceito para publicação em 18 de novembro de 2016.

${ }^{2}$ Docente do Núcleo de Educação em Ciências Agrárias, Universidade Federal de Sergipe (UFS), Avenida 26 de Setembro 1126, N.S. da Glória, SE 49680-000, Brasil. E-mails: edivaldorosas@gmail.com; *Autor para correspondência: arthurnascimento@gmail.com

${ }^{3}$ Pós-Graduando em Ciência Veterinária, Universidade Federal Rural de Pernambuco (UFRPE), Rua Dom Manoel de Medeiros s/n, Dois Irmãos, Recife, PE 52171-900, Brasil. E-mail: diogodmfs@hotmail.com

${ }^{4}$ Docente do Departamento de Morfologia e Fisiologia Animal, UFRPE, Rua Dom Manoel de Medeiros s/n, Dois Irmãos, Recife, PE 52171-900, Brasil.E-mails: manoeladriao@yahoo.com.br, anaporto@dmfa.ufrpe.br

${ }^{5}$ Docente do Departamento de Medicina Veterinária, UFRPE, Rua Dom Manoel de Medeiros s/n, Dois Irmãos, Recife, PE 52171-900, Brasil. E-mail: aurea@dmv.ufrpe.br
}

volvimento folicular. Os folículos classificados morfologicamente como antrais (terciários e pré-ovulatórios) foram aspirados manualmente para obtenção dos oócitos e células do cumulus. Os folículos pré-antrais (secundários) foram extraídos do córtex ovariano, por microdissecção, e os oócitos retirados. Nos dois grupos, os oócitos foram desnudados e agrupados em "pools" de dez células cada (Grupo A, n=10; Grupo B, n=10) e dez amostras com grupos de células do cumulus (Grupo $A 1, n=10, B 1, n=10$ ). O mRNA foi extraído e convertido em cDNA utilizando a técnica da RT-PCR, utilizando Oligo DT randômico para o mRNA. A análise da expressão confirmou a expressão gênica para IGF-2 nos grupos de oócitos e células do cumulus. Houve um aumento da expressão relativa do mRNA para IGF-2 nos grupos de oócitos durante a fase mais tardia do desenvolvimento folicular e as diferenças foram consideradas significantes $(p<0,05)$. Não houve variação significante 
da expressão de IGF2 entre os grupos de células do cumulus. Conclui-se que o fator de crescimento IGF-2 tem níveis mais elevados de expressão em oócitos ovinos, na segunda fase do desenvolvimento folicular, mas expressão semelhante em células do cumulus durante as fases estudadas do desenvolvimento folicular.

TERMOS DE INDEXAÇÃO: mRNA paraIGF-2, oócitos, cúmulus, folículos, PCR, ovócitos, gene, ovelhas, Santa Inês.

\section{INTRODUÇÃo}

0 processo de crescimento e a maturação folicular são controlados por uma perfeita interação entre fatores endócrinos, autócrinos e parácrinos. Diversos estudos têm comprovado que os fatores de crescimento, como EGF, FGF, IGF, TGF-ß e KL são de grande importância durante este processo, os quais podem atuar de diferentes formas sobre todas as fases da foliculogênese. Estes fatores de crescimento, que são produzidos pelo oócito, células da granulosa e células da teca, frequentemente atuam modulando os efeitos de FSH e LH (Van den Hurk \& Zhao 2005).

Os fatores de crescimento semelhantes à insulina, também conhecidos como somatomedinas ou IGF (do inglês: Insulin-like growth factor) são polipeptídeos com sequências altamente similares a da insulina. Os IGFs são parte de um sistema complexo que as células usam para se comunicar com o seu ambiente fisiológico que consiste em dois receptores de superfície (IGFR-1 e IGFR-2), dois ligantes (IGF-1 e IGF-2), uma família de seis proteínas de ligação de IGF de alta afinidade (IGFBP 1-6), bem como enzimas degradantes da IGFBP, referidas coletivamente como proteases (Pierce et al. 2001).

O IGFR-1 funciona como receptor para os dois tipos de IGF, enquanto que o IGFR-2 tem maior afinidade para IGF-2 (Jones \& Clemmons 1995). Ambos receptores de IGF estão presentes em células da granulosa de folículos primários, secundários e antrais (Monget et al. 1989).

Diversas evidências têm mostrado que um sistema formado pelo IGF e IGFBP exerce importantes funções no controle do desenvolvimento folicular e atresia em animais domésticos (Monget et al. 2002, Costa et al. 2014). Na maioria das espécies mamíferas, o IGF aumenta a proliferação de células da granulosa, a esteroidogênese e o crescimento do oócito (Silva et al. 2009).

No tocante ao IGF-2, este é expresso nas células da granulosa de folículos saudáveis e atrésicos (Zhou et al. 1996). Foi demonstrado que IGF-2 aumenta a síntese de DNA em células da granulosa após o cultivo in vitro de folículos pré-antrais caprinos (Rajarajan et al. 2006). Em ovários ovinos, o IGF-2 é apontado como o principal componente do sistema IGF, apresentando grande importância para o crescimento de pequenos folículos antrais nesta espécie (Hastie \& Haresign 2006).

A foliculogênese pode ser desregulada quando um determinado fator de crescimento está ausente (Eppig 2001). Em ovelhas e outros ruminantes, a nutrição influencia diretamente a fertilidade através do fornecimento de nutrientes específicos requeridos para os processos de desenvol- vimento oocitário, ovulação, fertilização e sobrevivência embrionária (Boland et al. 2001).

Dietas não balanceadas fornecidas no período precedente à fecundação influenciam negativamente a qualidade do oócito e o desenvolvimento embrionário (Papadopoulos et al. 2001, Lozano et al. 2003, Arruda et al. 2013). Em ovinos, Pisani et al. (2008) demonstraram que a disponibilidade de nutrientes no período pré-acasalamento pode alterar a expressão de genes do oócito envolvidos no sucessivo desenvolvimento embrionário. Paralelamente, em outros estudos, foi relatada uma redução na taxa de oócitos clivados em ovelhas alimentadas com dietas, contendo baixa ou elevada disponibilidade de energia (Borowczyk et al. 2006).

São ainda desconhecidos os níveis de expressão do mRNA para fatores de crescimento em ovelhas criadas extensivamente sem suplementação alimentar no estado de Pernambuco. Diante da importância e escassez desses dados, objetivou-se avaliar a expressão do mRNA para o gene IGF-2 em oócitos e células do cumulus de ovelhas em diferentes estágios do desenvolvimento folicular.

\section{MATERIAL E MÉTODOS}

Foram coletados ovários de ovelhas de raças nativas abatidas no matadouro municipal de Caruaru/PE e transportados para o Laboratório de Fisiologia Animal Molecular Aplicada (FAMA)/UFR$\mathrm{PE}$, onde foram avaliados o tamanho e o número de folículos.

Os oócitos e células do cumulus foram aspirados manualmente (seringa $10 \mathrm{ml}$ com agulha de $0,7 \times 25$ ) dos folículos classificados morfologicamente como antrais (terciários e pré-ovulatórios, 3,1-6,0mm) e separados em uma lupa com auxílio de pipeta, formando amostras com "pools" de dez células cada (Grupo A, $\mathrm{n}=10$ ). As células do cumulus foram desnudadas dos oócitos por pipetagem e estes grupos de células foram armazenados separadamente (Grupo A1, n=10). Já os oócitos provenientes de folículos classificados como pré-antrais (secundários, 1,0-3,0mm) foram extraídos do córtex ovariano, previamente fatiado com lâmina, microdissecados com auxílio de estereomicroscópio e também separados em "pools" de dez células (Grupo B; $n=10$ ). As células do cumulus, após os oócitos terem sido desnudados, formaram grupos celulares seguindo o mesmo padrão (Grupo B2; $\mathrm{n}=10$ ).

O RNA foi extraído dos ovócitos e das células do cumulus utilizando o kit RNeasy ${ }^{\circledR}$ Micro (QIAGEN ${ }^{\circledR}$ ) de acordo com o protocolo do fabricante.

Para obtenção do DNA complementar total (cDNA) foi utilizado o Kit ImProm-II(TM) Reverse Transcription System (Promega) seguindo as recomendações do fabricante. 0 cDNA foi obtido pela técnica de RT-PCR, utilizando Oligo DT randômico.

As amostras de cDNA de células do cumulus foram submetidas a avaliação no espectrofotômetro (BioMate ${ }^{\mathrm{TM}} 3$ da Thermo $^{\circledR}$ ) para determinar sua concentração, na diluição 1:250.

Não foi realizada a identificação das concentrações das amostras de oócitos no espectrofotômetro, já que se tem como pressuposto que todas as amostras de oócitos apresentavam o mesmo número de células, sendo a sua variação relacionada à expressão de mRNA (Caixeta et al. 2009). Não foi possível utilizar este mesmo procedimento com as células do cumulus já que foi inviável a contagem de células por amostra. Neste caso, foi necessário medir a concentração de cDNA e utilizar sempre a mesma quantidade de cDNA na amplificação.

Para a reação em cadeia da polimerase (PCR), as amostras foram amplificadas utilizando os primers do gene IGF-2 (Caixeta 
Quadro 1. Sequência do primer, tamanho, homologia e código de acesso dos genes IGF-2 e GAPDH

\begin{tabular}{lcccc}
\hline Gene & Sequência do primer & Tamanho (bp) & Homologia & GenBank \\
\hline IGF-2 & F: 5'CTTCAGCCGACCATCCAGCCGCATAAAC3' & & & \\
& R: 5'TCAGCGGACGGTGACTCTTGGCCTCTCT3' & 323 & $97 \%$ & X53554.1 \\
GAPDH & F: 5'GAAATCCCATCACCATCTTCCAGG3' & & & \\
& R: 5'GAGCCCAGCCTTCTCCATG3' & 153 & $100 \%$ & AF030943
\end{tabular}
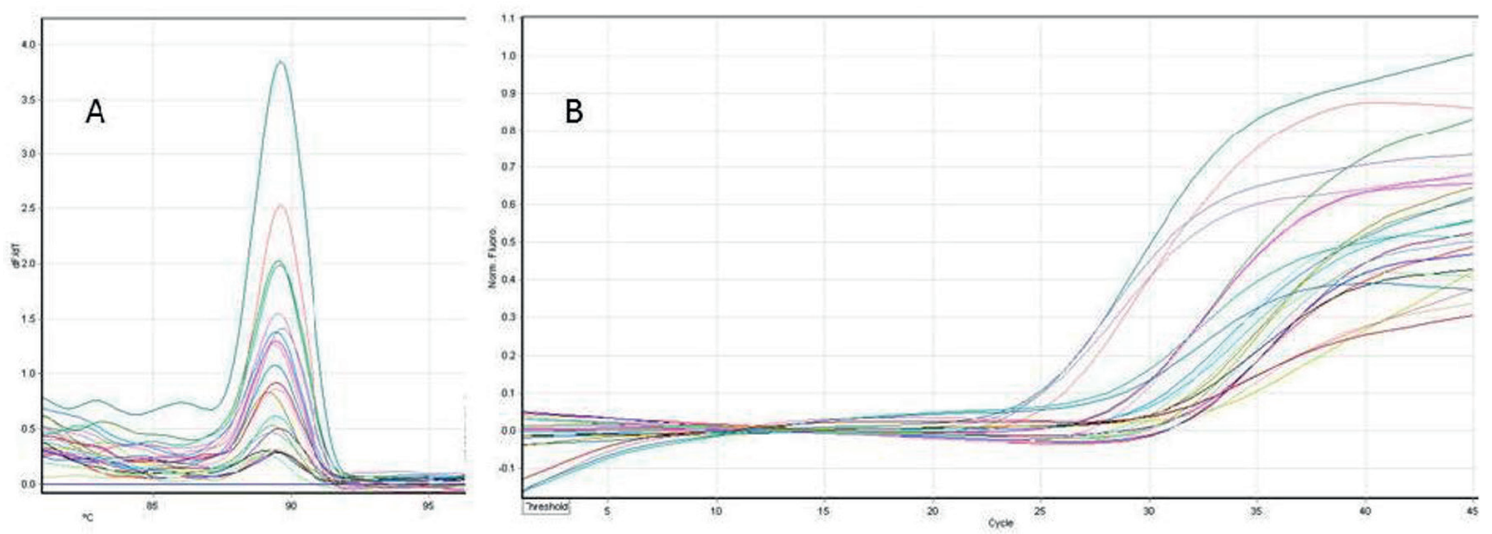

Fig.1. qPCR: (A) Melting e (B) curva de amplificação para o gene IGF-2.

et al. 2009) e do controle endógeno (gene de referência) GAPDH (Glyceraldehyde-3-phosphate dehydrogenase) (Quadro 1).

Para cada amostra, a PCR foi realizada em um volume final de $25 \mu \mathrm{L}$ com $2,5 \mu \mathrm{L}$ de $10 \mathrm{X}$ PCR, $1,75 \mu \mathrm{L}$ de $\mathrm{MgCl}_{2}(50 \mathrm{mM}), 0,5 \mu \mathrm{L}$ de cada primer (10pmol), 2,5 $\mu \mathrm{L}$ de dNTP $(2 \mathrm{mM}), 15 \mu \mathrm{L}$ de água ultra-pura, 0,8 U Taq DNA polimerase, 100 ng de DNA.

Os fragmentos foram amplificados empregando-se 35 ciclos a $94^{\circ} \mathrm{C}$ por 30 segundos, $53,7^{\circ} \mathrm{C}$ por 40 segundos, e $70^{\circ} \mathrm{C}$ por 30 segundos, seguidos por $72^{\circ} \mathrm{C}$ por 4 min. O DNA amplificado foi analisado em gel de agarose $(1,5 \%)$, com marcador de peso molecular DNA-Ladder 50 bp, corado com Blue Green Loading Dye (LGC Biotecnologia), visualizado em luz ultravioleta e fotografado para constatar sua amplificação).

As reações de qPCR foram realizadas utilizando o equipamento termociclador Real Time (Rotor-Gene Q da Qiagen ${ }^{\circledR}$ ) e kit de amplificação Qiagen - Quantifast ${ }^{\mathrm{TM}}$ SYBR Green PCR Handbook.

Em cada reação foram utilizados $1,5 \mu \mathrm{L}$ do cDNA (75ng), 7,5 $\mu \mathrm{L}$ do Qiagen - Quantifast ${ }^{\mathrm{TM}}$ SYBR Green PCR Handbook, 0,5 $\mu \mathrm{L}$ de primer sense e anti-sense $(10 \mathrm{pM})$ e $5 \mu \mathrm{L}$ de $\mathrm{H}_{2} \mathrm{O}$, totalizando um volume final de $15 \mu \mathrm{L}$. Os seguintes ciclos foram empregados: temperatura inicial de $95^{\circ} \mathrm{C}$ por 5 min (ativação da enzima), 40 ciclos de $95^{\circ} \mathrm{C}$ por 15 segundos e $60^{\circ} \mathrm{C}$ por 30 segundos. As condições do Melting foram: temperatura inicial: 95 a $65^{\circ} \mathrm{C}$, com incremento de $0,5^{\circ} \mathrm{C} / 5$ segundos.

Os valores de $\mathrm{C}_{\mathrm{T}}$ foram transformados pelo método delta-delta- $\mathrm{C}_{\mathrm{T}}$ e normalizados pela expressão relativa de mRNA, usando o GAPDH como controle endógeno da expressão.

0 efeito do tamanho dos folículos e consequente fase do desenvolvimento folicular sobre a expressão de IGF-2 foi comparado por análise de variância (ANOVA) e as diferenças entre médias foram avaliadas pelo teste de Tukey, sendo as diferenças significantes quando $\mathrm{p}<0,05$. Toda a análise estatística foi realizada utilizando o programa SAS (version 9.2; SAS Institute, Cary, NC, USA).

\section{RESULTADOS}

Como resultado da amplificação, foram obtidos fragmentos em torno de 323bp com o primer IGF-2. A análise da expressão na qPCR confirmou a expressão gênica para IGF-2

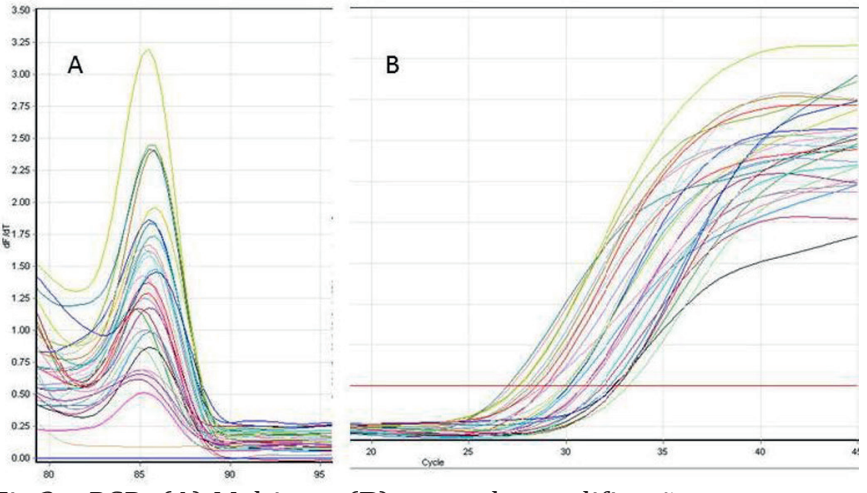

Fig.2. qPCR: (A) Melting e (B) curva de amplificação para o gene GAPDH.

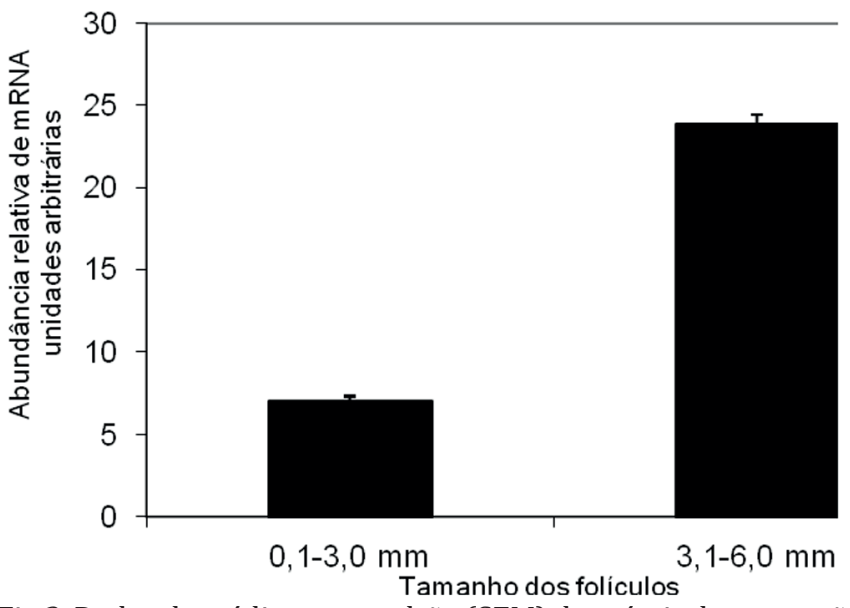

Fig.3. Dados da média \pm erro padrão (SEM) dos níveis de expressão do mRNA de IGF-2 determinados por PCR real time em oócitos ovinos provenientes de folículos em diferentes tamanhos $(0,1-$ 3,0 e 3,1-6,0 mm) e respectivos estágios (pré-antrais e antrais) do desenvolvimento folicular. Os dados foram normalizados com o gene do controle endócrino GAPDH e os resultados relativos expressos usando o método $\Delta \Delta \mathrm{C}_{\mathrm{T}^{*}}(\mathrm{p}<0,05)$ 


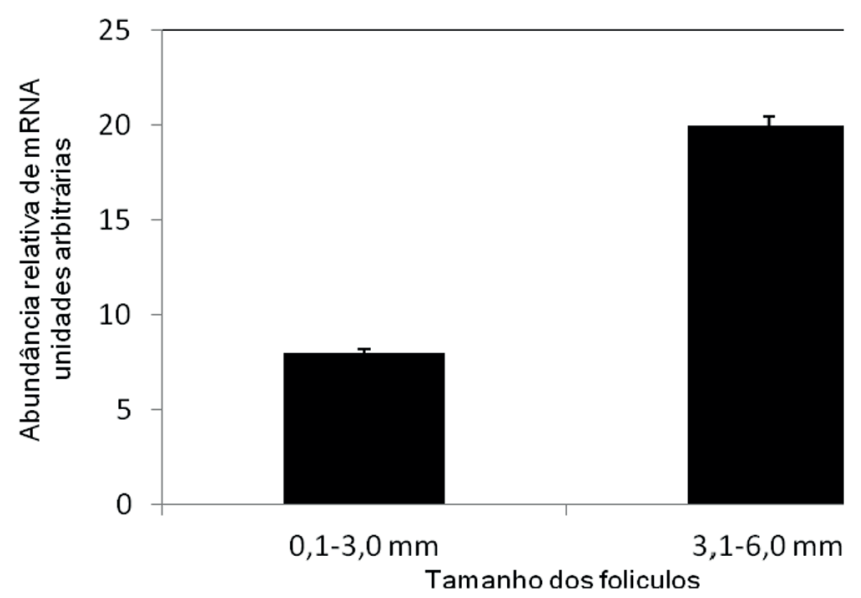

Fig.4. Dados da média terro padrão (SEM) dos níveis de expressão do mRNA de IGF-2 determinados por PCR real time em células do cumulus de ovinos provenientes de folículos em diferentes tamanhos (0,1-3,0 e 3,1-6,0 mm) e respectivos estágios (pré-antrais e antrais) do desenvolvimento folicular. Os dados foram normalizados com o gene do controle endócrino GAPDH e os resultados relativos expressos usando o método $\Delta \Delta \mathrm{C}_{\mathrm{T}} \cdot(\mathrm{p}<0,05)$

(Fig.1) nos grupos de oócitos e células do cumulus, utilizando o GAPDH (Fig.2) como gene de referência.

Houve um aumento da expressão relativa do mRNA para IGF-2 nos grupos de oócitos durante a fase mais tardia do desenvolvimento folicular e as diferenças foram consideradas significantes $(\mathrm{p}<0,05)$ (Fig.3).

Não houve variação significante da expressão de IGF2 entre os grupos de células do cumulus (Fig.4).

\section{DISCUSSÃO}

Em oócitos e células do cumulus, o IGF-2 é expresso no início do período de desenvolvimento e continua sendo expresso ao longo do estágio antral avançado, sugerindo que este gene é requerido para o desenvolvimento de folículos pré-ovulatórios de ovelhas, concordando com os resultados de Monget et al. (2002).

Muitos dados conflitantes têm sido relatados para o sistema IGF. Transcrições de IGF-2 foram detectadas em células da teca, células do cumulus e os oócitos (Yuan et al. 1996, Yaseen et al. 2001, Nuttinck et al. 2004, Hastie \& Haresign 2006, Caixeta et al. 2009). Os resultados obtidos para a expressão do mRNA de IGF-2 em células do cumulus são semelhantes aos obtidos em bovinos por Caixeta et al. (2009), não havendo variação significante ao decorrer dos estágios foliculares $(p>0,05)$. Estes pesquisadores detectaram transcrição de IGF-2 em células do cumulus de bovinos, no entanto, não associaram os níveis de IGF-2 a um potencial de desenvolvimento folicular.

Em ovários ovinos, o IGF-2 é apontado como o principal componente do sistema IGF, apresentando grande importância para o crescimento de pequenos folículos antrais nesta espécie (Hastie \& Haresign 2006), o que pode explicar o aumento significante $(\mathrm{p}<0,05)$ dos níveis de IGF- 2 nos oócitos de folículos maiores que 3,1 mm (Grupo A) em relação ao grupo de folículos pré-antrais (Grupo B).
Porém, os resultados obtidos em células da teca por Perks et al. (1995) e Monget et al. (1996) em ovinos, e Armstrong et al. (1998) em bovinos, demonstraram expressões maiores para mRNA de IGF-2 em folículos no início do desenvolvimento, utilizando hibridização in situ.

Mais tarde, em estudos realizados em bovinos (Yuan et al. 1998) e equinos (Watson et al. 2004), pesquisadores obtiveram maiores níveis de expressão do mRNA para IGF-2 nas células da teca em folículos antrais. Os resultados obtidos neste estudo corroboram com esses resultados mais recentes e indicam que o aumento da expressão de IGF-2, em folículos pré-ovulatórios, pode aumentar a biodisponibilidade do sistema IGF no meio intrafolicular em comparação com os folículos anovulatórios, e assim contribuir para o aumento da esteroidogênese e subsequente ovulação desses folículos.

Segundo Silva et al. (2009), o sistema IGF tem ação direta no crescimento dos oócitos e na proliferação das células da granulosa em folículos antrais. Esta ação do IGF nas células da teca (Watson et al. 2004), granulosa e nos oócitos (Silva et al. 2009) pode estar diretamente relacionada com os resultados obtidos neste trabalho que confirmaram uma maior expressão de IGF-2 em oócitos extraídos de folículos maiores que $3,1 \mathrm{~mm}$, indicando uma relação direta entre estes tipos celulares no controle sob os fatores de crescimento e, consequentemente, no desenvolvimento folicular.

\section{CONCLUSÃO}

Conclui-se que o fator de crescimento IGF-2 tem níveis mais elevados de expressão, em oócitos ovinos, na segunda fase do desenvolvimento folicular, mas expressão semelhante em células do cumulus durante as fases estudadas. Mais estudos envolvendo a relação dos demais fatores de crescimento e o desenvolvimento folicular de ovelhas nativas são necessários para avaliar a relação desta função reprodutiva com as características genéticas das ovelhas nativas deste Estado.

Agradecimentos.- À Professora Dra. Áurea Wischral, Universidade Federal Rural de Pernambuco, pela orientação e conhecimento científico depositados neste trabalho. Aos colegas do Laboratório de Fisiologia Animal Molecular Aplicada (FAMA-UFRPE). À Fundação de Amparo à Ciência e Tecnologia de Pernambuco (FACEPE), pela concessão de bolsa de doutorado.

\section{REFERÊNCIAS}

Armstrong D.G., Baxter G., Gutierrez C.G., Hogg C.O., Glazyrin A.L., Campbell B.K., Bramley T.A. \& Webb R. 1998. Insulin-like growth factor binding protein -2 and -4 messenger ribonucleic acid expression in bovine ovarian follicles: effect of gonadotropins and developmental status. Endocrinology 139:2146-2154.

Arruda I.J., Silva L.M., Oliveira C.H.A., Silva A.M., Rodrigues F.V., Fernandes C.C.L., Silva C.M.G., Adriao M., Araujo A.A. \& Rondina D. 2013. Produção de embriões in vivo e expressão dos genes IGF-IR, IGF-II, GLUT-I e HSP 70.1 em embriões de cabras alimentadas com bagaço de caju desidratado ou raspa de mandioca. Revta Bras. Ciênc. Vet. 20:54-58.

Boland M.P., Lonergan P. \& O'Callaghan D. 2001. Effect of nutrition on endocrine parameters, ovarian physiology, and oocyte and embryo development. Theriogenology 55:1323-1340.

Borowczyk E., Caton J.S., Redmer D.A., Bilski J.J., Weigl R.M., Vonnahme K.A., Borowicz P.P., Kirsch J.D., Kraft K.C., Reynolds L.P. \& Grazul-Bilska 
A.T. 2006. Effects of plane of nutrition on in vitro fertilization and early embryonic development in sheep. J. Anim. Sci. 84:1593-1599.

Caixeta E.S., Ripamonte P., Franco M.M., Buratini J. \& Dode M.A.N. 2009. Effect of follicle size on mRNA expression in cumulus cells and oocytes of Bos indicus: an approach to identify marker genes for developmental competence. Reprod. Fertil. Develop. 21:655-664.

Costa S.L., Costa E.P., Pereira E.C.M., Benjamin L.A., Rodrigues M.T., Mendes V.R.A. \& Silva T.F. 2014. Influence of Insulin-like Growth Factor I (IGF-I) on the survival and the in vitro development of caprine preantral follicles. Pesq. Vet. Bras. 34(10):1037-1044.

Eppig J.J. 2001. Oocyte control of ovarian follicular development and function in mammals. Reproduction 122:829-838.

Hastie P.M. \& Haresign W. 2006. A role for LH in the regulation of expression of mRNAs encoding components of the insulin-like growth factor (IGF) system in the ovine corpus luteum. Anim. Reprod. Sci. 96:196-209.

Jones J.I. \& Clemmons D.R. 1995. Insulin-like growth factors and their binding proteins: biological actions. Endocrine Reviews 16:3-34.

Lozano J.M., Lonergran P., Boland M.P. \& O'Callaghan D. 2003. Influence of nutrition on the effectiveness of superovulation programmes in ewes: effect on oocyte quality and postfertilization development. Reproduction 125:543-553.

Monget P., Besnard N., Huet C., Pisselet C., Benne F., Gasser F., Hatey F., Mulsant P., Tomanek M. \& Monniaux D. 1996. Role of the IGF system in the sheep ovary, p.85-100. In: LeRoith D. (Ed.), The Role of Insulin-like Growth Factors in Ovarian Physiology. Ares-Serono Symposia Publications, Rome.

Monget P., Fabre S., Mulsant P., Lecerf F., Elsen J.M., Mazerbourg S., Pisselet C. \& Monniaux D. 2002. Regulation of ovarian folliculogenesis by IGF and BMP system in domestic animals. Domestic Anim. Endocrinol. 23:139-154.

Monget P., Monniaux D. \& Durand P. 1989. Localization, characterization, and quantification of insulin-like growth factor-I-binding sites in the ewe ovary. Endocrinology 125:2486-2493.

Nuttinck F., Charpigny G., Mermillod P., Loosfelt H., Meduri G., Freret S., Grimard B. \& Heyman Y. 2004. Expression of components of the insulin-like growth factor system and gonadotropin receptors in bovine cumulus-oocyte complexes during oocyte maturation. Domestic Anim. Endocrinol. 27:179-195.

Papadopoulos S., Lonergan P., Gath V., Quinn K.M., Evans A.C., O'Callaghan D. \& Bolan M.P. 2001. Effect of diet quantity and urea supplementation on oocyte and embryo quality in sheep. Theriogenology 55:1059-1069.

Perks C.M., Denning-Kendall P.A., Gilmour R.S. \& Wathes D.C. 1995. Localization of messenger ribonucleic acids for insulin-like growth factor-I
(IGF-I), IGF-II, and the type I receptor in the ovine ovary throughout the estrus cycle. Endocrinology 136:5266-5273.

Pierce S.B., Costa M., Wisotzk E.Y.R., Devadhar S., Homburger S.A., Buchman A.R., Ferguson K.C., Heller J., Platt D.M., Pasquinelli A.A., Liu L.X., Doberstein S.K. \& Ruvkun G. 2001. Regulation of DAF-2 receptor signaling by human insulin and ins-1, a member of the unusually large and diverse C. elegans insulin gene family. Genes and Development 15:672686.

Pisani L.F., Antonini S., Pocar P., Ferrari S., Brevini T.A.L., Rhind B.S.M. \& Gandolfi F. 2008. Effects of pre-mating nutrition on mRNA levels of developmentally relevant genes in sheep oocytes and granulosa cells. Reproduction 136:303-312.

Rajarajan K., Rao B.S., Vagdevi R., Tamilmani G., Arunakumari G., Sreenu M., Amarnath D., Naik B.R. \& Rao V.H. 2006. Effect of various growth factors on the in vitro development of goat preantral follicles. Small Rumin. Res. 63:204-212.

Silva J.R.V., Figueiredo J.R. \& Van Den Hurk R. 2009. Involvement of growth hormone (GH) and insulin-like growth factor (IGF) system in ovarian folliculogenesis. Theriogenology 71:1193-1208.

Van Den Hurk R. \& Zhao J. 2005. Formation of ovarian follicles and their growth, differentiation and maturation within ovarian follicles. Theriogenology 63:1717-1751.

Watson E.D., Bae S.E., Thomassen R., Thomson S.R.M., Woad K. \& Armstrong D.G. 2004. Insulin-like growth factors-I and -II and insulin-like growth factor-binding protein-2 in dominant equine follicles during spring transition and the ovulatory season. Reproduction 128:321-329.

Yaseen M.A., Wrenzycki C., Herrmann D., Carnwath J.W. \& Niemann H. 2001. Changes in the relative abundance of mRNA transcripts for insulin-like growth factor (IGF-I and IGF-II) ligands and their receptors (IGFIR/IGF-IIR) in preimplantation bovine embryos derived from different in vitro systems. Reproduction 122:601-610.

Yuan W., Bao B., Garverick Ha., Youngquist Rs. \& Lucy Mc. 1998. Follicular dominance in cattle is associated with divergent patterns of ovarian gene expression for insulin-like growth factor (IGF)-I, IGF-II, and IGF binding protein-2 in dominant and subordinate follicles. Domestic Anim. Endocrinol. 1:55-63.

Yuan W., Lucy M.C. \& Smith M.F. 1996. Messenger ribonucleic acid for insulin-like growth factors-I and -II, insulin-like growth factor-binding protein-2, gonadotropin receptors, and steroidogenic enzymes in porcine follicles. Biology Reprod. 55:1045-1054.

Zhou J., Adesanya O.O., Vatzias G., Hammond J.M. \& Bondy C.A. 1996. Selective expression of insulin-like growth factor system components during porcine ovary follicular selection. Endocrinology 137:4893-4901. 